Supplement of The Cryosphere, 10, 2763-2777, 2016

http://www.the-cryosphere.net/10/2763/2016/

doi:10.5194/tc-10-2763-2016-supplement

(C) Author(s) 2016. CC Attribution 3.0 License.

(c) (1)

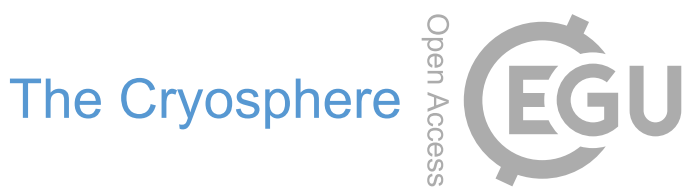

Supplement of

\title{
Surface mass balance and water stable isotopes derived from firn cores on three ice rises, Fimbul Ice Shelf, Antarctica
}

\section{P. Vega et al.}

Correspondence to: Carmen P. Vega (carmen.vega@geo.uu.se)

The copyright of individual parts of the supplement might differ from the CC-BY 3.0 licence. 

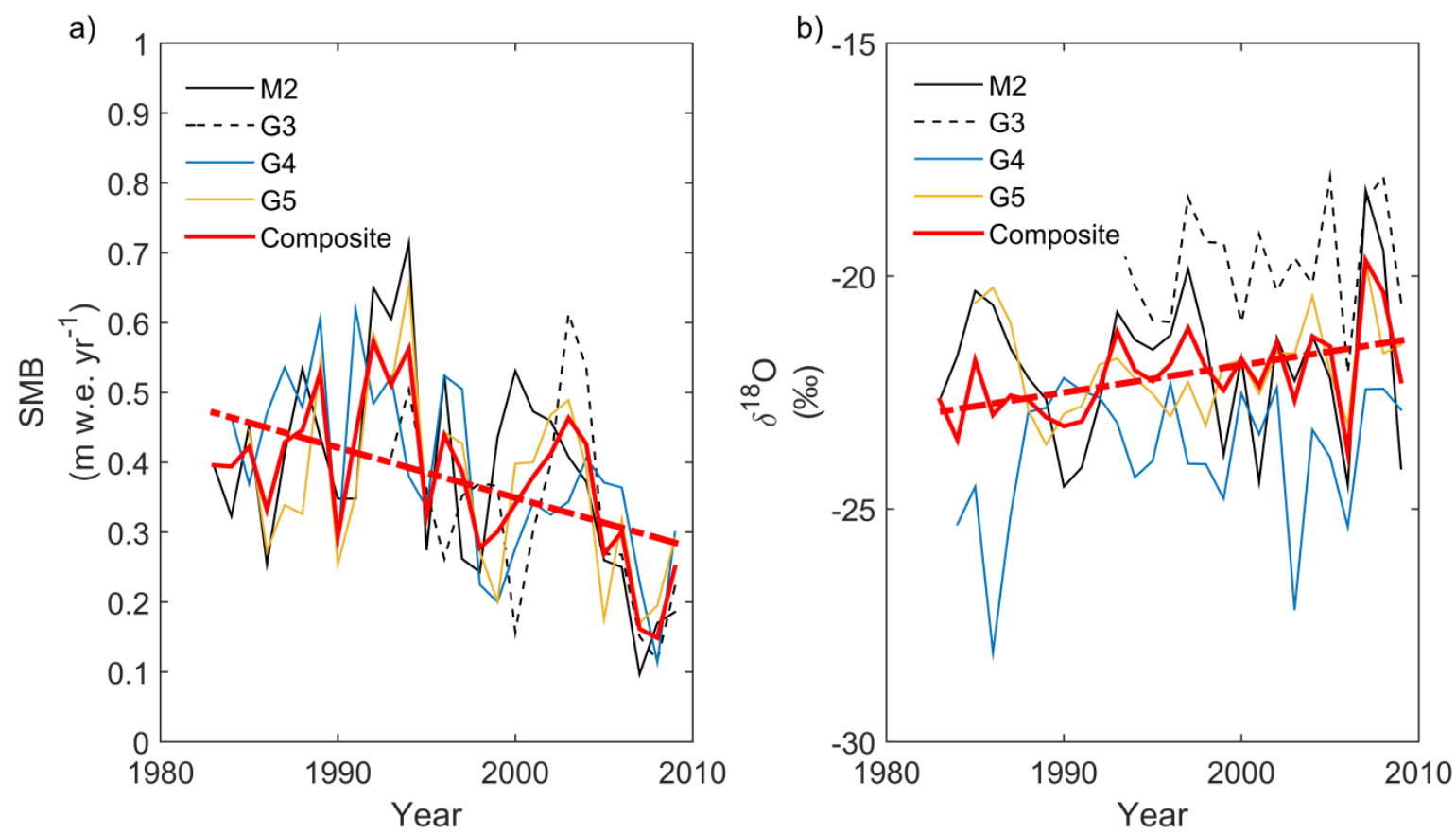

Figure S1: a) Annual SMB, and b) mean annual $\delta^{18} \mathrm{O}$ for M2, G3, G4, G5 and the composite FIS core record (Schlosser et al., 2014). The dashed red line indicates the linear regression in the composite core for the period (1983-2009) shown in Figure 5 and 9 for SMB and $\delta^{18} \mathrm{O}$, respectively. 